\title{
A 3-in-1 doping process for interdigitated back contact solar cells exploiting the understanding of co-diffused dopant profiles by use of PECVD borosilicate glass in a phosphorus diffusion
}

\author{
Sebastian Gloger* , Axel Herguth, Josh Engelhardt, Giso Hahn and Barbara Terheiden \\ University of Konstanz, Department of Physics, Universitätsstr. 10, Konstanz, 78457, Germany
}

\begin{abstract}
Boron and phosphorus doping of crystalline silicon using a borosilicate glass (BSG) layer from plasma enhanced chemical vapor deposition (PECVD) and phosphorus oxychloride diffusion, respectively, is investigated. More specifically, the si multaneous and interacting diffusion of both elements through the BSG layer into the silicon substrate is characterized in depth. We show that an overlying BSG layer does not prevent the formation of a phosphorus emitter in silicon substrates during phosphorus diffusion. In fact, a BSG layer can even enhance the uptake of phosphorus into a silicon substrate com pared with a bare substrate.

From the understanding of the joint diffusion of boron and phosphorus through a BSG layer into a silicon substrate, a model is developed to illustrate the correlation of the concentration dependent diffusivities and the emerging diffusion pro files of boron and phosphorus. Here, the in diffusion of the dopants during diverse doping processes is reproduced by the use of known concentration dependences of the diffusivities in an integrated model. The simulated processes include a BSG drive in step in an inert and in a phosphorus containing atmosphere.

Based on these findings, a PECVD BSG/capping layer structure is developed, which forms three different $\mathrm{n}^{++}, \mathrm{n}^{+}$ and $\mathrm{p}^{+}$doped regions during one single high temperature process. Such engineered structure can be used to produce back contact solar cells. Copyright (c) 2016 John Wiley \& Sons, Ltd.
\end{abstract}

\section{KEYWORDS}

doping; co diffusion; boron; phosphorus; silicon; solar cell; borosilicate glass (BSG); interdigitated back contact (IBC)

* Correspondence

Sebastian Gloger, University of Konstanz, Department of Physics, Universitätsstr. 10, Konstanz, 78457, Germany.

E mail: sebastian.gloger@uni konstanz.de

\section{INTRODUCTION}

About $90 \%$ of solar cells manufactured in 2014 were based on crystalline silicon [1,2]. Eighty percent of these cells use aluminum back surface fields (BSF [3]) [4]. However, their efficiency is limited to less than $20 \%$ because of the mediocre internal reflection and surface passivation of the aluminum contact [5]. The efficiency of solar cells can be increased up to $25 \%$ with back contact solar cell concepts [6] omitting the trade off between low shading and resistance losses. To realize such concepts, differently doped regions are needed on the rear side of a solar cell. These regions can conveniently be cre ated in separate steps of deposition and in diffusion of dopants using plasma enhanced chemical vapor deposition (PECVD) silicate glass or other standard doping processes.
Recent research has focused on the formation process of PECVD silicate glass emitters [7 9], monitoring the quality of these PECVD emitters [10], co diffusion processes with PECVD emitters [11,12], contacting of these emitters $[13,14]$, passivation through the same BSG layer [15], and the fabrication of solar cells using PECVD silicate glass [7 9,12,14,16 19]. Solar cell efficiencies of above $20 \%$ have been achieved with PECVD silicate glass processes for $\mathrm{n}$ type small area back junction IBC cell concepts [16], large area back junction [18,19], and front junction bifacial solar cell concepts [14]. Evidence for interacting diffusion phenomena have also been reported using a BSG layer and phosphorus oxychloride $\left(\mathrm{POCl}_{3}\right)$ diffusion $[15,17]$.

The objective of this study is therefore to reveal the interacting diffusion phenomena of boron and phosphorus 
in crystalline silicon. The co diffusion processes of boron and phosphorus through a BSG layer are investigated experimentally, and a model allowing for the prediction of co diffused dopant profiles is presented. Furthermore, we introduce an industrially feasible process to fabricate three differently doped regions, phosphorus $\mathrm{n}^{++}, \mathrm{n}^{+}$, and boron $\mathrm{p}^{+}$doped, using one single high temperature step for highly efficient interdigitated back contact silicon solar cells.

\section{MODEL OF THE DIFFUSION OF DOPANTS IN SILICON}

As a basis for the studies on dopant diffusion in crystalline silicon, using borosilicate glass, a model of the diffusion of dopants is introduced. It is developed as an integrated model to simulate the isolated in diffusion of boron and of phosphorus as well as the joint and interacting in diffusion of boron and phosphorus through a borosilicate layer into a silicon substrate.

\subsection{Theory of diffusion (Fick's law)}

The diffusion of dopants like phosphorus (P) and boron (B) in silicon can be described by Fick's first law of diffusion

$$
j_{\mathrm{P}}=D_{\mathrm{P}} \operatorname{grad} c_{\mathrm{P}}, \quad j_{\mathrm{B}}=D_{\mathrm{B}} \operatorname{grad} c_{\mathrm{B}} .
$$

Here $D$ denotes the diffusivity and $j$ the particle current density of the respective dopant, which is opposing the gradient of its concentration $c$. The dopants are preserved according to the continuity equation

$$
\frac{\partial c_{\mathrm{P}}}{\partial t}=\operatorname{div} j_{\mathrm{P}}, \quad \frac{\partial c_{\mathrm{B}}}{\partial t}=\operatorname{div} j_{\mathrm{B}} \quad \frac{\partial r_{\mathrm{B}}}{\partial t}
$$

In the case of boron, a source term accounts for a boron reservoir $r_{\mathrm{B}}$ in the BSG layer.

The diffusivity of the dopants depends on the tempera ture, following an Arrhenius dependence as seen later on in the results section.

\subsection{Determination of the diffusivity by Boltzmann-Matano analysis}

The diffusivity $D$ of a dopant can be determined by means of Boltzmann Matano analysis from a diffused depth profile $c(x)$ of the dopant [20]. Therefore, the diffusivity of the dop ant may depend exclusively on its concentration. To deter mine $D(c)$ the diffusion equation is rearranged [21 23]. The diffusivity $D$ of a specific concentration $c^{*}$ equals the in verse function $x(c)$ of the doping profile $c(x)$, integrated from the substrate concentration $c_{0}$ to the concentration $c^{*}$, multi plied with its negative differential at the position $c^{*}$, and di vided by twice the diffusion duration $t$ [20],

$$
D\left(c^{*}\right)=\frac{1}{2 t}\left(\frac{\mathrm{d} x}{\mathrm{~d} c}\right)_{c} \int_{c^{*}}^{c_{c_{0}}^{*}} x \mathrm{~d} x
$$

\subsection{Simulation of diffusion processes}

Solar cells and their manufacturing processes can be simu lated using software like Sentaurus [24,25]. The diffusion processes in this study can already be described by a simpler model. Therefore, the diffusion and continuity equations of the dopants will be solved directly for the conditions as relevant within these investigations. In this way the effects to be investigated can be deduced clearly.

For the simulation of the in diffusion of boron and phos phorus only the diffusion of dopants is described with concentration dependent diffusivities in silicon. Diffusion of point defects and their interaction with dopants is not modeled independently. Furthermore, no interface effects like an oxi dation of the silicon substrate and effects linked to it like the generation of point defects or segregation, which may lead to a formation of precipitates, are taken into account. Also the diffusion in the borosilicate glass layer is described by a constant diffusivity only, and the uptake of phosphorus from the diffusion furnace atmosphere is not modeled. Despite this strong simplification of the diffusion process, the model describes well the depth profiles and the observed effects of mutual decrease and enhancement of the diffusion of dopants. Diverse diffusion processes can be predicted with it.

To simulate the diffusion of dopants into a silicon sub strate, the partial differential equations (1) and (2) are solved in one dimension for the conditions of the respec tive investigation. This is carried out numerically with the software FlexPDE [26] using the finite element method [27]. The following three processes are simulated with one collective model:

$\mathrm{POCl}_{3}$ diffusion: $\mathrm{POCl}_{3}$ diffusion is simulated as diffusion of phosphorus into a silicon substrate. Here a constant concentration of phosphorus is adopted at the surface of the substrate. There is no boron.

BSG diffusion in $\mathrm{N}_{2}$ atmosphere: BSG diffusion in an inert nitrogen atmosphere is simulated as diffusion of boron from an overlying BSG layer into the silicon bulk. Here a certain concentration of boron in the BSG is used, which defines the surface concentration of boron in the silicon substrate. There is no phosphorus. $B S G$ diffusion in $\mathrm{POCl}_{3}$ diffusion furnace: BSG diffusion in a $\mathrm{POCl}_{3}$ diffusion furnace is simulated as concurrent diffusion of boron and phosphorus. Boron diffuses from a BSG layer into a silicon substrate while phosphorus diffuses through the borosilicate glass into the silicon substrate. 
The change of the diffusivity of boron and phosphorus in crystalline silicon because of the respective other dopant [28 31] is taken into account.

The modeled sample structure consists of a silicon sub strate with an overlying BSG of thickness $d_{\mathrm{BSG}}$, see Figure 1 . In the case of $\mathrm{POCl}_{3}$ diffusion, the BSG thickness is assumed as zero. The two layers distinguish by different concentra tions and diffusivities of the dopants. The formation of a phosphosilicate glass (PSG) [32,33] and the transport of phosphorus onto the substrate are not modeled separately. Instead the surface concentration of phosphorus is used as a parameter to describe the amount of phosphorus, which is available at the surface of the sample.

\subsection{Diffusion of substitutional dopants}

Dopants of group III and V of the periodic table, like boron and phosphorus, form covalent bonds with their surround ing silicon lattice atoms [34], and are almost exclusively built in substitutionally $[21,35]$. They diffuse mainly be cause of interaction with the two intrinsic point defects, va cancies, and interstitial silicon atoms $[21,34,35]$. Because their diffusion takes place through mobile dopant defect pairs, the diffusivity $D_{\mathrm{A}}$ of a dopant depends on both, the concentration of the intrinsic point defect that governs its diffusion and the concentration of the dopant itself [22].

From the concentration $c_{\mathrm{X}}{ }^{m}$ of a point defect $\mathrm{X}^{-m}$ in charge state $m$, the concentration of dopant defect pairs $c_{\mathrm{AX}}{ }^{m}$ can be developed. Using the sum of the current den sities of the diffusing dopant defect pairs $D_{\mathrm{AX}}{ }^{m}$, the diffu sivity $D_{\mathrm{A}}$ of the dopant emerges as $[34,35]$

$$
D_{\mathrm{A}}=h \sum_{m} D_{\mathrm{AX}^{m_{i}}}\left(\frac{n}{n_{i}}\right)^{m}
$$

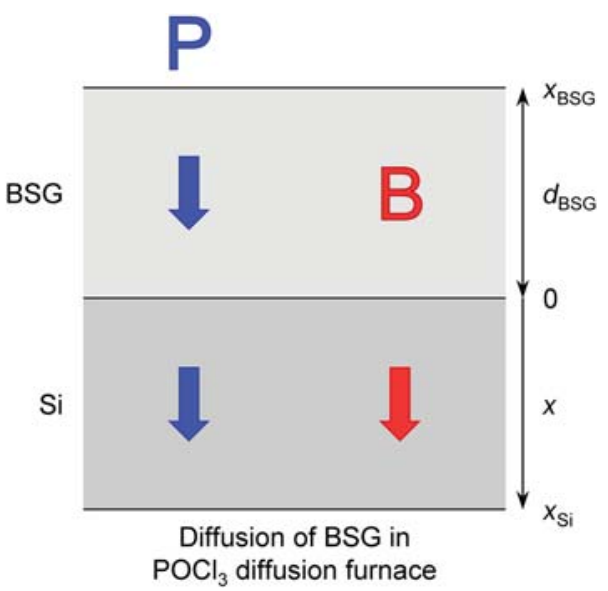

Figure 1. Sketch of the model of a BSG diffusion step in a $\mathrm{POCl}_{3}$ diffusion furnace. Boron and phosphorus diffuse simultaneously into a silicon substrate. with the intrinsic diffusivities of the diffusing species $D_{\mathrm{AX}}{ }^{m} i$ and the field enhancement factor $h$.

\subsection{Parameterization of the diffusivity of phosphorus}

Under intrinsic conditions $\left(n<n_{\mathrm{i}}\right)$, the diffusion of phospho rus in silicon takes place through neutral silicon interstitials [22,35 37] and for high phosphorus concentrations through double negatively charged vacancies $[22,36,38]$. So for the diffusivity of phosphorus $D_{\mathrm{P}}$ a simple model is used, which assumes a different diffusivity in the kink and in the tail region and whose parameters are chosen based on the phosphorus profiles shown in Figure 2. The diffusivity of phosphorous is depicted in Figure 3. For its parameterization according to equation (4) and [38] the following relations are used as pre sented in [39] ( $c_{\mathrm{B}}$ : boron concentration; $c_{\mathrm{Pa}(\mathrm{S})}$ : electrically ac tive phosphorus (surface) concentration; $c_{\mathrm{Peff}}=c_{\mathrm{Pa}} \quad c_{\mathrm{B}}$ : effective phosphorus net doping; $n_{\mathrm{P}}$ constant):

$$
D_{\mathrm{PK}}=D_{\mathrm{PK} 0}\left(1+\left(\frac{c_{\text {Peff }}}{n_{\mathrm{P}}}\right)^{2}\right),
$$

Diffusivity of phosphorus in kink region

$$
D_{\mathrm{PT}}=D_{\text {РT0 }}\left(1+\left(\frac{c_{\mathrm{PaS}}}{n_{\mathrm{P}}}\right)^{3}\right),
$$

Diffusivity of phosphorus in tail region

$$
D_{\mathrm{TE}}=\left(\begin{array}{ll}
D_{\mathrm{PT}} & D_{\mathrm{PK}}
\end{array}\right) \frac{1}{\exp \left(\frac{c_{\mathrm{Pa}}-n_{\mathrm{p}}}{n_{\mathrm{P}}}\right)+1} .
$$

Diffusivity enhancement in tail region

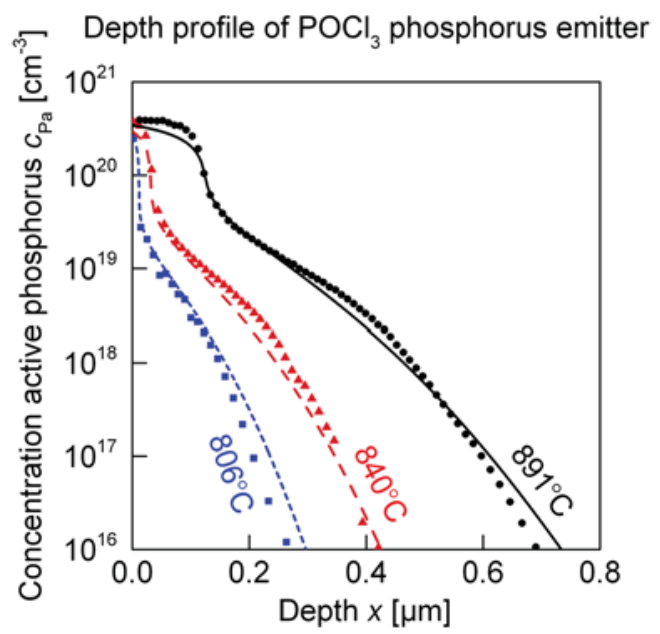

Figure 2. Phosphorus depth profiles experimentally produced by a $\mathrm{POCl}_{3}$ diffusion (ECV measurement, symbols) and simulated according to section 2 (lines). The electrically active concentration of phosphorus $C_{\mathrm{Pa}}$ is plotted against the depth in the substrate $x$ for a diffusion temperature $T$ of 806,840 , and $891^{\circ} \mathrm{C}$. 


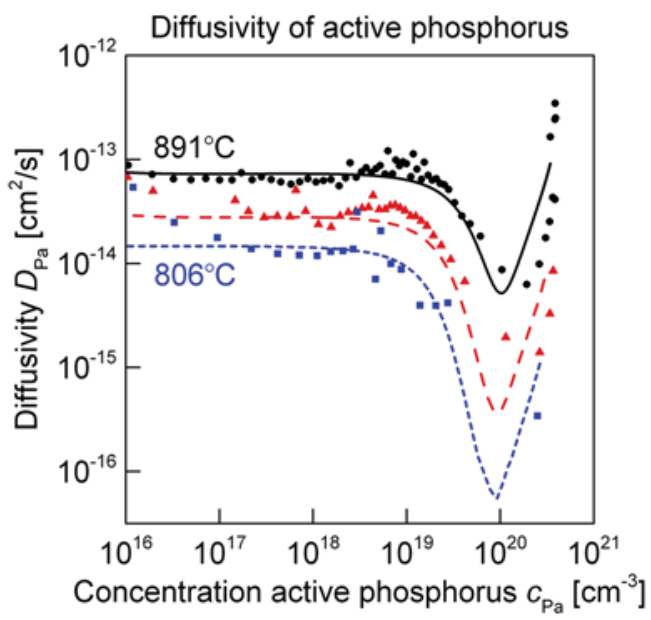

Figure 3. Diffusivity $D_{\mathrm{Pa}}$ of the electrically active phosphorus plotted against its concentration $c_{\mathrm{Pa}}$. Values determined by Boltzmann Matano analysis from the phosphorus emitter pro files in Figure 2 are shown for $T=806,840$, and $891^{\circ} \mathrm{C}$ (sym bols) together with the values of the diffusivity model (lines).

Furthermore, for a high concentration of effective boron net doping $c_{\mathrm{Beff}}=c_{\mathrm{B}} \quad c_{\mathrm{Pa}}$ in $\mathrm{p}$ type silicon a proportional de crease of the diffusivity according to $\left(1+c_{\mathrm{Beff}} / n_{\mathrm{i}}\right)^{-1}$ is taken into account [30,31], which is shown in Figure 4. So the over all diffusivity of phosphorus emerges as

$$
D_{\mathrm{P}}=\left(D_{\mathrm{PK}}+D_{\mathrm{TE}}\right) \frac{1}{1+\frac{c_{\text {Beff }}}{n_{\mathrm{i}}}} .
$$

The process temperature exceeds the glass transition and flow temperatures of borosilicate glass, which lie at about

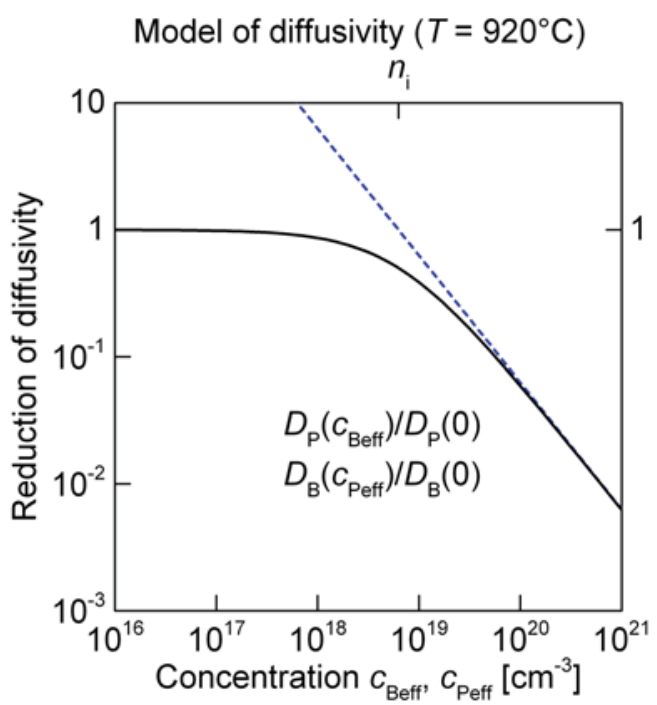

Figure 4. Decrease of the diffusivity of boron and phosphorus plotted against the concentration of the respective other dopant. $D_{\mathrm{P}}\left(c_{\text {Beff }}\right) / D_{\mathrm{P}}\left(c_{\text {Beff }}=0\right)=\left(1+c_{\text {Beff }} / n_{\mathrm{i}}\right) \quad 1$ and $D_{\mathrm{B}}\left(c_{\text {Peff }}\right) / D_{\mathrm{B}}\left(c_{\text {Peff }}=0\right)$ $=\left(1+C_{\text {Peff }} / n_{\mathrm{i}}\right) \quad 1$ (continuous black line) and the asymptote $n_{i} / C_{\text {Beff }}$ $n_{i} / C_{\text {Peff }}$ (dashed blue line) are shown for a temperature $T=920^{\circ} \mathrm{C}$.
$600{ }^{\circ} \mathrm{C}$ [40] and 800 to $850^{\circ} \mathrm{C}$ [41], respectively. Therefore, the diffusivity of phosphorus in the BSG layer $D_{\mathrm{BSG}}$ is modeled with a higher value than in the crystalline silicon sub strate. Values of $4 \times 10^{-10}$ to $3 \times 10^{-12} \mathrm{~cm}^{2} / \mathrm{s}$ arise for it from the experimentally determined doping profiles.

\subsection{Parameterization of the diffusivity of boron}

Boron diffuses in silicon together with neutral and positively charged silicon interstitials [34 36,42,43]. For the diffusiv ity of boron also a simple model is used. Its parameters are chosen based on the boron profiles shown in Figure 5. The diffusivity of boron is parameterized after equation (4) by the following relation according to [39] and shown in Figure 6.

$$
D_{\mathrm{Be}}=D_{\mathrm{Bi}}\left(1+\frac{c_{\mathrm{Beff}}}{n_{\mathrm{i}}}\right) \text { Extrinsic diffusivity of boron }
$$

For a high concentration of effective phosphorus net dop ing $c_{\mathrm{Peff}}=c_{\mathrm{Pa}} \quad c_{\mathrm{B}}$ in $\mathrm{n}$ type silicon a proportional decrease of the diffusivity according to $\left(1+c_{\text {Peff }} / n_{\mathrm{i}}\right)^{-1}$ is taken into account $[28,29]$, see Figure 4 . So the overall diffusivity of boron emerges as

$$
D_{\mathrm{B}}=\left(D_{\mathrm{Be}}+D_{\mathrm{TE}}\right) \frac{1}{1+\frac{c_{\text {Peff }}}{n_{\mathrm{i}}}} .
$$

The diffusivity of boron in the BSG layer is modeled with the same value as the diffusivity of phosphorus. It is distinctly higher than $D_{\mathrm{B}}$ in silicon and therefore not limit ing the diffusion process.

The boron and phosphorus concentrations are parame terized as presented in [39]. For the overall concentration

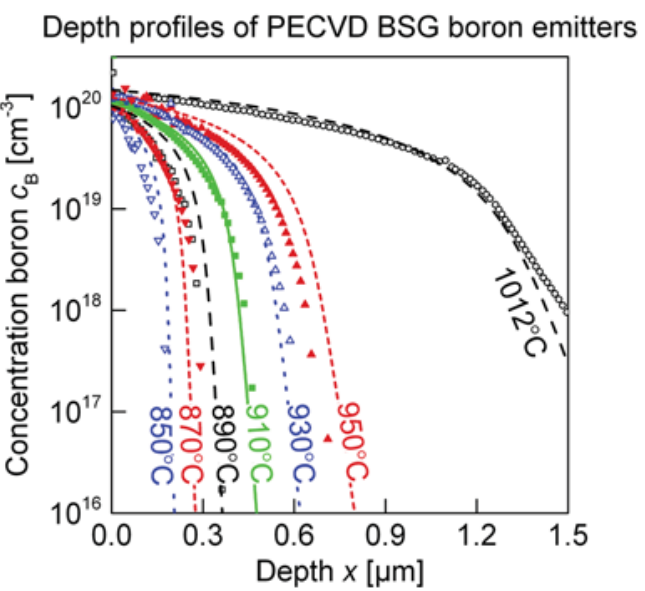

Figure 5. Depth profiles of boron emitters produced experimen tally with PECVD borosilicate glass $\left(d_{\mathrm{BSG}}=73 \mathrm{~nm}\right)$ in an inert $\mathrm{N}_{2}$ atmosphere (ECV measurement, symbols) and simulated (lines). The concentration of boron $c_{B}$ is plotted against the depth in the substrate $x$ for a diffusion temperature $T$ of $850,870,890,910$, 930, 950, and $1012^{\circ} \mathrm{C}$ for $100 \mathrm{~min}$. 


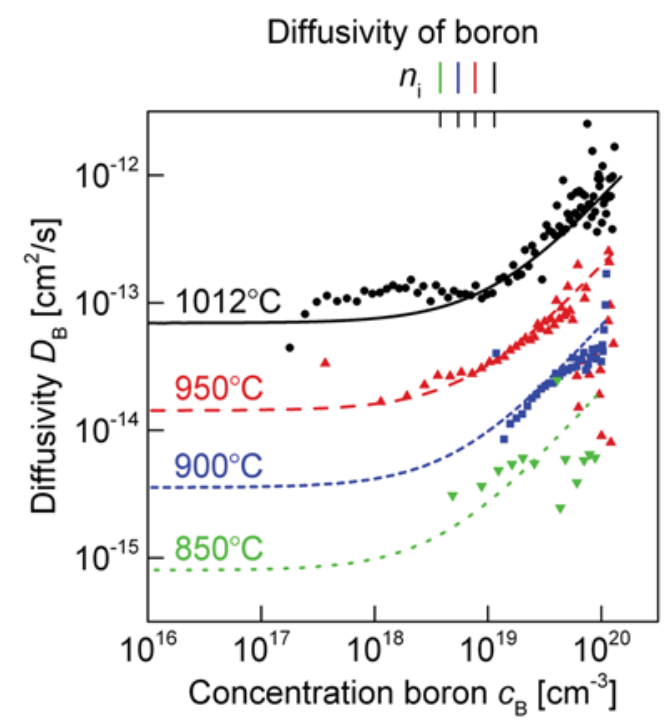

Figure 6. Diffusivity $D_{\mathrm{B}}$ of the dopant boron plotted against its concentration $c_{\mathrm{B}}$. Values determined by Boltzmann Matano analysis from the boron emitter profiles in Figure 5 are shown for $T=850,900,950$ and $1012^{\circ} \mathrm{C}$ (symbols). The diffusivity's dependence on $c_{\mathrm{B}}$ and $T$ is fitted with $D_{\mathrm{B}}=2.8 \mathrm{exp}(3.5 \mathrm{eV} /$ $\left.k_{\mathrm{B}} T\right)\left(1+\left(c_{\mathrm{B}} / n_{\mathrm{i}}\right)\right) \mathrm{cm}^{2} / \mathrm{s}$ (lines).

of boron in the BSG layer at the start of the process a value of $5 \times 10^{21} \mathrm{~cm}^{-3}$ is used, which is estimated by inductively coupled plasma spectrometry.

\subsection{Solving of the differential equations}

The simulated depth profiles of the dopants phosphorus $c_{\mathrm{P}}(x, t)$ and boron $c_{\mathrm{B}}(x, t)$ follow with time the partial differential equations (1) and (2) taking into account the diffusivities $D_{\mathrm{P}}$ from equation (8) and $D_{\mathrm{B}}$ from equation (10) as well as the boundary conditions of the concentration $c_{\mathrm{P}}$ and $c_{\mathrm{B}}$ of the dopants for the respective process.

The values of the solubilities and the Arrhenius fits of the diffusivities $\left(D_{\mathrm{PK} 0}, D_{\mathrm{PT} 0}, n_{\mathrm{P}}, D_{\mathrm{Bi}}\right)$ of the dopants phos phorus and boron in silicon are determined by investiga tions of the respective dopant profiles without counter doping and in agreement with literature values, see [39]. With this model the joint in diffusion of both dopants can be reproduced.

\section{EXPERIMENTAL DETAILS}

\subsection{Sample preparation}

(100) orientated, phosphorus doped $\mathrm{n}$ type and boron doped $\mathrm{p}$ type float zone (FZ) and Czochralski $(\mathrm{Cz})$ silicon substrates with an area of $50 \times 50 \mathrm{~mm}^{2}$ are used to manu facture doping samples. The FZ silicon substrates have a thickness of $250 \mu \mathrm{m}$, the $\mathrm{Cz}$ substrates $180190 \mu \mathrm{m}$.
The saw damage at the surfaces of the $\mathrm{Cz}$ silicon sam ples is removed in a chemical polish (CP) [44 47] or in di luted sodium hydroxide solution $(\mathrm{NaOH})$ [47]. Afterwards the samples are cleaned in diluted hydrochloric acid $(\mathrm{HCl})$ and diluted fluoric acid (HF) and undergo a RCA cleaning $[48,49]$. The RCA cleaning consists of the steps SC1, HF, $\mathrm{SC} 2, \mathrm{HF}$. Before and after these immersions the samples are rinsed in deionized water.

The samples receive a direct plasma enhanced chemical vapor deposition (PECVD) of $\mathrm{SiO}_{\mathrm{x}} \mathrm{N}_{\mathrm{y}} \mathrm{B}_{\mathrm{z}}: \mathrm{H}$ layer, which will be denoted as borosilicate glass (BSG) in the following [50]. For this purpose an Oxford Instruments Plasmalab 100 System with silane $\left(\mathrm{SiH}_{4}\right)$, nitrous oxide $\left(\mathrm{N}_{2} \mathrm{O}\right)$, diborane $\left(\mathrm{B}_{2} \mathrm{H}_{6}\right)$, and hydrogen $\left(\mathrm{H}_{2}\right)$ as precursor gases is used. Diborane is diluted to $0.5 \%$ in hydrogen. The PECVD BSG layer has an average thickness of 27 or $73 \mathrm{~nm}$ and a boron concentration of $(5 \pm 1) \times 10^{21} \mathrm{~cm}^{-3}$, a silicon con centration of $(1.4 \pm 0.2) \times 10^{22} \mathrm{~cm}^{-3}$, and a refractive index of 1.5 at a wavelength of $633 \mathrm{~nm}$.

Some samples receive a silicon nitride layer $\left(\mathrm{SiN}_{\mathrm{x}}: \mathrm{H}\right)$ [50] which is deposited in the same PECVD system, to mask the substrate against an in diffusion of phosphorus during a high temperature step in a phosphorus diffusion furnace. The $\mathrm{SiN}_{\mathrm{x}}: \mathrm{H}$ layer has a thickness of $70 \mathrm{~nm}$ and a refractive index of 2.0 at a wavelength of $633 \mathrm{~nm}$.

The samples are heated in a Centrotherm horizontal tube furnace at atmospheric pressure to diffuse boron from the BSG layer into the silicon substrate. This diffu sion step is carried out at temperatures of $8501012{ }^{\circ} \mathrm{C}$ for $100 \mathrm{~min}$ in nitrogen atmosphere $\left(\mathrm{N}_{2}\right)$ in an oxidation tube or in a phosphorus oxychloride diffusion tube $\left(\mathrm{POCl}_{3}\right)$.

\subsection{Characterization}

The thickness of the deposited layers is determined with a Woollam V VASE ellipsometer [51] in the wavelength range of $3001000 \mathrm{~nm}$. After the diffusion step, the borosilicate glass layer is dissolved in dilute hydrofluoric acid with a concentra tion of 0.5 to $25 \%$. The concentration of boron, phosphorus, and silicon of the dissolved BSG layer is determined by induc tively coupled plasma spectrometry.

The sheet resistivity of the emitter is determined by means of four terminal sensing [52]. The depth profile of the net dopant concentration is determined by electrochemical ca pacitance voltage $(E C V)$ profiling $[22,53]$ with a WEP CVP21 wafer profiler. For selected samples the dopant pro files are determined by secondary ion mass spectrometry (SIMS) $[22,54]$ using a Cameca IMS 4f spectrometer.

\section{RESULTS}

\subsection{PECVD BSG emitter diffused-in in nitrogen atmosphere}

The depth profile $c_{\mathrm{B}}(x)$ of a boron emitter, which is pro duced by a borosilicate glass layer with a thickness of 
$d_{\mathrm{BSG}}=73 \mathrm{~nm}$ on $\mathrm{n}$ type substrates, is shown in Figure 5 for diffusion temperatures of $8501012{ }^{\circ} \mathrm{C}$ for $100 \mathrm{~min}$. With rising temperature, the depth of the emitter increases. Its boron concentration continuously declines from the sur face. The surface concentration of the boron emitter matches well the solubility of boron in silicon [55 58]. Therefore, the used borosilicate glass works as an unlim ited diffusion source $[59,60]$.

In Figure 6 the diffusivity of the dopant boron $D_{\mathrm{B}}$ obtained by Boltzmann Matano analysis with equation (3) is plotted against its concentration $c_{\mathrm{B}}$. It increases with rising temperature. Furthermore, it increases in the extrinsic area with rising boron concentration. It is fitted according to equation (9) with

$$
D_{\mathrm{B}}=2.8 \exp \left(\frac{3.5 \mathrm{eV}}{k_{B} T}\right)\left(1+\frac{c_{\mathrm{B}}}{n_{\mathrm{i}}}\right) \frac{\mathrm{cm}^{2}}{\mathrm{~s}} .
$$

The determined diffusivity $D_{\mathrm{B}}$ matches values pre sented in [55] and [61].

The profiles of the prepared emitters are well reproduced by the simulation, see Figure 5. Deviations emerge mainly because of a scattering of the produced emitters through process inaccuracies.

\subsection{PECVD BSG emitter with $\operatorname{SiN}_{x}: H$ capping layer}

The BSG boron emitter profiles with and without $\mathrm{SiN}_{\mathrm{x}}: \mathrm{H}$ capping correspond well with each other. The boron con centration is slightly reduced with a capping layer. When the diffusion step is carried out in a phosphorus diffusion tube, the phosphorus concentration in the substrate is less than $1 \times 10^{17} \mathrm{~cm}^{-3}$.

Thus, PECVD BSG emitters can be produced with a sil icon nitride capping layer. Also, the capping layer works as a diffusion barrier and prevents a compensating in diffusion of phosphorus into the silicon substrate, see also [62 66].

\subsection{PECVD BSG without $\operatorname{SiN}_{x}$ :H capping layer in phosphorus diffusion}

In this part of the investigation the in diffusion of phos phorus during a conventional $\mathrm{POCl}_{3}$ diffusion into a silicon substrate coated with a PECVD BSG layer without a capping layer is determined. Here, silicon substrates with a BSG layer and unmasked substrates are exposed to a $\mathrm{POCl}_{3}$ diffusion at a temperature of $832^{\circ} \mathrm{C}$ and a duration of $44 \mathrm{~min}$. With this process conventional phos phorus profiles arise independently of the presence of a BSG layer, revealing a high diffusivity of phosphorus in the BSG.

The phosphorus depth profile, which occurs with and without a PECVD BSG layer, is shown together with the re spective simulated phosphorus profile in Figure 7. The depth profile exhibits the kink and tail region usually observed for a phosphorus diffusion. It is hardly affected by the BSG layer. Furthermore, only small differences occur with and

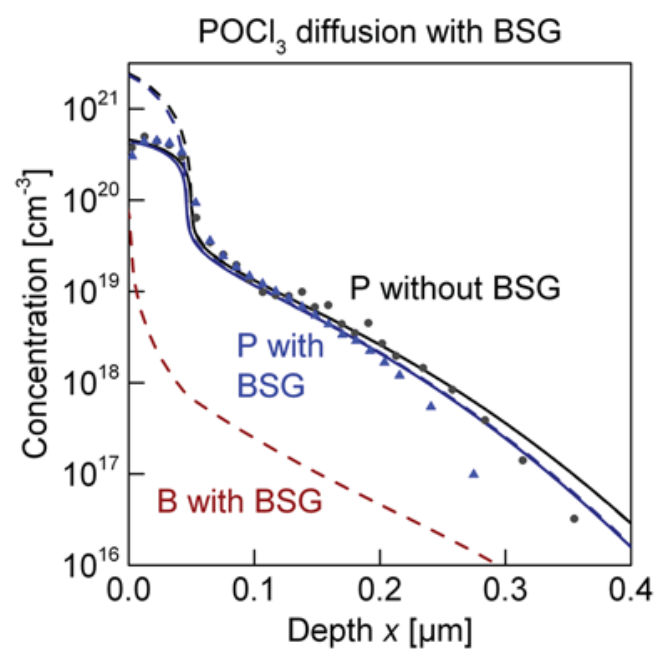

Figure 7. Depth profile of phosphorus after a $\mathrm{POCl}_{3}$ diffusion $\left(T=832^{\circ} \mathrm{C}, t=44 \mathrm{~min}\right)$ with a BSG layer $\left(d_{\mathrm{BSG}}=27 \mathrm{~nm}\right)$ and with out it (symbols). The effective phosphorus concentration $c_{\text {Peff }}$ determined by ECV measurements is plotted against the depth in the substrate $x$. The sheet resistivity $R_{\square}$ of the phosphorus pro file with BSG layer is $58 \Omega / \square$ and $56 \Omega / \square$ without. Further, the sim ulated profiles with and without BSG are shown for the active phosphorus concentration $C_{\mathrm{Pa}}$ (continuous lines) and for the total phosphorus $C_{P}$ and boron concentration $C_{B}$ (dashed lines).

without BSG layer, like a slight drop of the surface concen tration and a slight reduction of phosphorus concentration for concentrations below $1 \times 10^{18} \mathrm{~cm}^{-3}$. The sheet resistivity of the occurring phosphorus profile with BSG layer is about $10 \%$ higher than the resistivity without BSG layer.

The phosphorus profile with and without PECVD BSG layer is well matched by the simulation. Further, the simulation yields a completely compensated convex boron profile, which is accompanied by a low diffusiv ity of boron compared to phosphorus and a reduction of the boron diffusivity in the kink region of the phos phorus profile.

\subsection{Boron diffusion from a PECVD BSG without capping in a $\mathrm{POCl}_{3}$ diffusion furnace}

The in diffusion of the dopants during a PECVD BSG diffu sion in a $\mathrm{POCl}_{3}$ diffusion furnace is determined. Here silicon substrates with a BSG layer and uncoated silicon substrates undergo a high temperature step of $920^{\circ} \mathrm{C}$ for $100 \mathrm{~min}$ in a $\mathrm{POCl}_{3}$ diffusion furnace. As process gas, nitrogen is used without addition of $\mathrm{POCl}_{3}$. Yet the inner walls of quartz tubes of the $\mathrm{POCl}_{3}$ diffusion furnace are coated with PSG by previous $\mathrm{POCl}_{3}$ diffusions and serve as a phosphorus source. Therefore, the BSG drive in process yields a phos phorus profile, which exhibits a completely compensated boron concentration. The high concentration of dopants leads to a mutual reduction of the diffusivity and hence to a convex boron profile. 
The phosphorus concentration of a PECVD BSG layer is determined to $(2.5 \pm 0.5) \times 10^{21} \mathrm{~cm}^{-3}$ after a diffusion step in a $\mathrm{POCl}_{3}$ diffusion furnace, with its inner walls coated with PSG by previous $\mathrm{POCl}_{3}$ diffusions. The depth profiles of the phosphorus and boron concentration with and without PECVD BSG layer are shown in Figure 8 together with the respective simulated depth profiles.

A phosphorus profile can be determined in case of a diffusion with and without BSG layer. In the case of sam ples without BSG layer the phosphorus profile has a much higher sheet resistivity and a much lower surface concen tration than a phosphorus profile arising at this temperature with an addition of $\mathrm{POCl}_{3}$. The concentration of the phos phorus profile emerging without BSG is much lower than the one arising with BSG. It does not exhibit a kink region.

In the case of samples with BSG, the phosphorus profile has a sheet resistivity much lower and a surface concentration much higher than without BSG. Also there is a completely compensated boron concentration besides the phosphorus concentration in the substrate with BSG layer. The boron concentration is much lower than the phosphorus concentra tion and proceeds convex.

The simulation matches well the profiles of the phospho rus and boron concentration with PECVD borosilicate glass.

The reduction of the concentration of the phosphorus profile compared to a $\mathrm{POCl}_{3}$ diffusion at this temperature without BSG and the steep concentration decrease of the phosphorus profile close to the surface are consequences

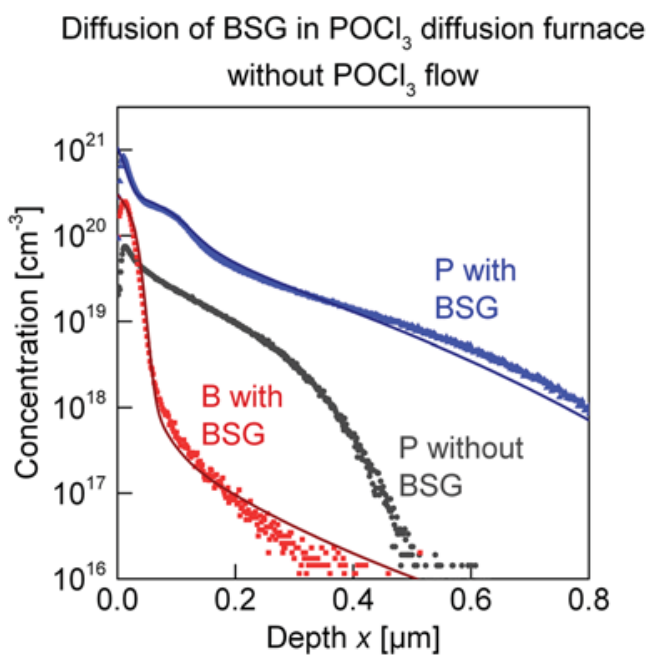

Figure 8. Depth profile of phosphorus and boron after a diffu sion step $\left(T=920^{\circ} \mathrm{C}, t=100 \mathrm{~min}\right)$ in a coated $\mathrm{POCl}_{3}$ diffusion furnace (no $\mathrm{POCl}_{3}$ flow) with BSG layer $\left(d_{\mathrm{BSG}}=73 \mathrm{~nm}\right.$ ) and with out. The total phosphorus $C_{P}$ and boron concentration $C_{B}$ with BSG as well as the total phosphorus concentration without BSG are plotted against the depth in the substrate $x$ (SIMS mea surement, symbols). The sheet resistivity $R_{\square}$ of the partially compensated phosphorus profile with BSG layer is $24 \Omega / \square$, the one without BSG layer is $56 \Omega / \square$. Furthermore, the simulated profiles of the total phosphorus and boron concentration with BSG layer are shown (lines). of the high boron concentration in this region, which decreases the phosphorus diffusivity, see also [30,31]. The high boron concentration close to the surface forms at the beginning of the diffusion step, when it is not yet over compensated by phosphorus. Likewise the high phosphorus concentration leads to a decrease of the boron diffusivity, see also $[28,29]$. The decrease of the boron diffusivity results in a convex boron profile, which is much lower than in the case of an in diffusion without phosphorus.

The boron concentration decreases steeply. This corre sponds to a low diffusivity. Hence the phosphorus concen tration, which decreases the boron diffusivity, is present early and the diffusivity of phosphorus in the BSG layer is high or phosphorus is taken up during heating up already, see also subsection 5.2. The diffusivity in the BSG becomes an important quantity for the profile of a BSG drive in step $\left(T>900{ }^{\circ} \mathrm{C}\right)$ in a $\mathrm{POCl}_{3}$ diffusion furnace. In contrast, the diffusivity of phosphorus in the BSG layer does not limit the formation of a phosphorus profile during a standard $\mathrm{POCl}_{3}$ diffusion $\left(T<850^{\circ} \mathrm{C}\right)$, see Figure 7 . This arises as a result of the reduction of the phosphorus diffusivity by the non compensated boron concentration at the beginning of the drive in step.

The simulated boron profile shows a concentration decrease with lower slope in the phosphorus tail region compared to the experimental boron profile and so a higher diffusivity of boron. This is seen as a result of the used pa rameterization of the boron diffusivity. A more detailed model of the boron diffusivity in general [61] and in this case of an overcompensated emitter push effect [28,29] taking into account the different diffusing species [38] is expected to correct the inaccuracy.

\section{DISCUSSION}

\subsection{Phosphorus uptake by borosilicate glass}

The use of a borosilicate glass layer on a silicon substrate during a $\mathrm{POCl}_{3}$ diffusion or a high temperature drive in step in a $\mathrm{POCl}_{3}$ diffusion furnace without any $\mathrm{POCl}_{3}$ flow leads to a simultaneous in diffusion of boron and phospho rus into the silicon substrate. This happens because of the boron concentration in the BSG layer, resulting in a low glass transition and flow temperature of the BSG [40,41] and with that in a high diffusivity of phosphorus. There fore, a BSG layer does not work as a diffusion barrier for phosphorus, unlike silicate glass without boron [62,63], which has a much higher glass transition and flow temper ature $[40,41,67]$. Thus phosphorus can diffuse from $\mathrm{POCl}_{3}$ present in the diffusion furnace through the BSG layer into the silicon substrate.

Furthermore, a BSG layer promotes an in diffusion of phosphorus into a silicon substrate during a high tempera ture step in a coated $\mathrm{POCl}_{3}$ diffusion furnace. This takes place by an enhanced phosphorus uptake from the 
atmosphere of the diffusion furnace compared to a bare silicon substrate. Without the addition of oxygen, more phosphorus is taken up in a borosilicate glass layer than on a bare silicon substrate, as oxygen is needed for the for mation of a PSG layer according to the reaction [22]

$$
4 \mathrm{POCl}_{3}+3 \mathrm{O}_{2} \rightarrow 2 \mathrm{P}_{2} \mathrm{O}_{5}+6 \mathrm{Cl}_{2} \text {. }
$$

In case of a BSG layer on the silicon substrate, oxygen can be provided from the BSG. Furthermore, a borosili cate or silicate glass layer exhibits compressive stress [68]. The stress is reduced with increasing phosphorus and boron fraction [69,70]. This also is assumed as a reason for the uptake of phosphorus in a borosilicate and silicate glass layer.

The used simple model of the diffusion of the two dop ants, phosphorus and boron, matches well the results deter mined experimentally for the different diffusion steps investigated exemplarily. Nonetheless, the use of a more detailed model of phosphorus [38,71 73] and boron dif fusion $[61,74]$ in the silicon bulk [36,76 78] but also of the BSG layer and the uptake of the dopants from the atmosphere of the diffusion furnace $[33,60,79,80]$ is expected to lead to an even better match of simulation and experiment.

\subsection{Diffusivity of the dopants in the borosilicate glass layer}

The diffusivity of the dopants in the borosilicate glass layer has a large effect on their depth profiles generated in the silicon substrate. To illustrate this, the simulated depth profiles of phosphorus and boron are shown respec tively in Figures 9 and 10 for different values of the

Simulated phosphorus depth profile arising from diffusion of $\mathrm{BSG}$ in $\mathrm{POCl}_{3}$ furnace

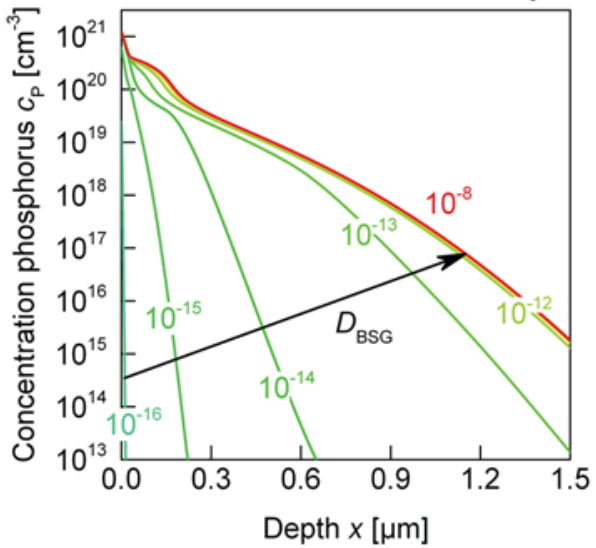

Figure 9. Simulated depth profile of phosphorus $C_{P}$ after a diffu sion step $\left(T=920^{\circ} \mathrm{C}, t=100 \mathrm{~min}\right)$ in a coated $\mathrm{POCl}_{3}$ diffusion furnace (no $\mathrm{POCl}_{3}$ flow) with BSG layer $\left(d_{\mathrm{BSG}}=27 \mathrm{~nm}\right)$. The dif fusivity in the BSG layer $D_{\mathrm{BSG}}$ is varied with decimal power from $10{ }^{16}$ to $10^{8} \mathrm{~cm}^{2} / \mathrm{s}$.
Simulated boron depth profile arising from diffusion of $\mathrm{BSG}$ in $\mathrm{POCl}_{3}$ furnace

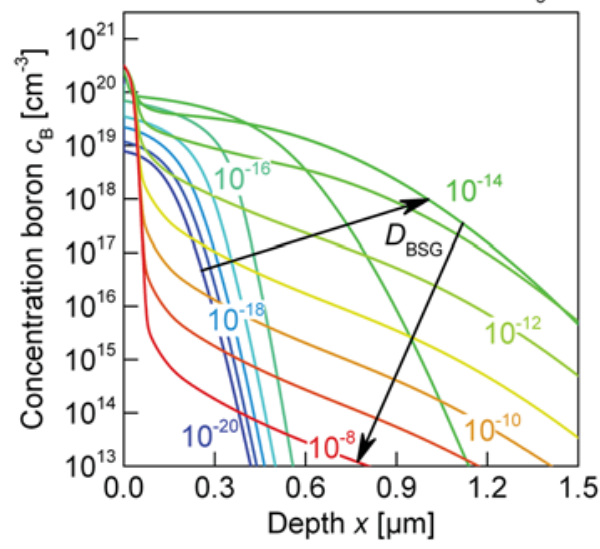

Figure 10. Simulated depth profile of boron $C_{B}$ after a diffusion step $\left(T=920^{\circ} \mathrm{C}, t=100 \mathrm{~min}\right)$ in a coated $\mathrm{POCl}_{3}$ diffusion furnace (no $\mathrm{POCl}_{3}$ flow) with a BSG layer $\left(d_{\mathrm{BSG}}=27 \mathrm{~nm}\right.$ ). The diffusivity in the BSG layer $D_{\mathrm{BSG}}$ is varied with decimal power from 1020 to $10^{8} \mathrm{~cm}^{2} / \mathrm{s}$.

diffusivity of the dopants $D_{\mathrm{BSG}}=D_{\mathrm{P}}$ in $\mathrm{BSG}=D_{\mathrm{B}}$ in BSG. Here, the in diffusion of boron from a PECVD BSG layer in a coated $\mathrm{POCl}_{3}$ diffusion furnace is simulated according to subsection 4.4 .

The simulated depth profiles of phosphorus are shown in Figure 9. For a low diffusivity of the dopants $D_{\mathrm{BSG}}$ no phosphorus enters the substrate. The BSG layer blocks the diffusion completely. Starting at a certain diffusivity, a depth profile of phosphorus arises in the substrate: According to Figure 9 at $D_{\mathrm{BSG}} \geq 10^{-16} \mathrm{~cm}^{2} / \mathrm{s}$ at a BSG layer thickness $d_{\mathrm{BSG}}$ of $27 \mathrm{~nm}$. With rising diffusivity a depth profile with increasing concentration of phosphorus develops. Figure 9 shows that from a certain high value of the diffusivity, $D_{\mathrm{BSG}} \geq 10^{-11} \mathrm{~cm}^{2} / \mathrm{s}$, the diffusion pro cess is no longer limited by the diffusivity in the BSG layer. For a further rise of the diffusivity $D_{\mathrm{BSG}}$ the phos phorus profile shows no heavier doping.

The simulated depth profile of boron is shown in Figure 10. For a low diffusivity of the dopants $D_{\mathrm{BSG}}$ a boron profile of shallow depth and low surface concen tration emerges, as the diffusion of boron into the silicon substrate is limited by the low diffusivity in the BSG layer, in Figure 10 for $D_{\mathrm{BSG}}=10^{-20} \mathrm{~cm}^{2} / \mathrm{s}$. For increasing diffusivity heavier doped depth profiles of bo ron with higher surface concentrations arise, in Figure 10 for $D_{\mathrm{BSG}}=10^{-19}$ to $10^{-16} \mathrm{~cm}^{2} / \mathrm{s}$. With a higher diffusivity the diffusion of phosphorus into the silicon substrate leads to the emitter push effect, resulting in much deeper boron profiles, in Figure 10 for $D_{\mathrm{BSG}} \geq 10^{-15} \mathrm{~cm}^{2} / \mathrm{s}$. For a further rising diffusivity, the increasing phosphorus concentration leads to a reduction of the boron diffusivity close to the surface of the silicon substrate, yielding a convex depth profile of boron, in Figure 10 for $D_{\mathrm{BSG}} \geq 10^{-13} \mathrm{~cm}^{2} / \mathrm{s}$. With increasing diffu sivity, the high phosphorus concentration is already 
present early during the BSG drive in process, reducing the diffusivity of boron in the silicon substrate already at an early stage, and thus resulting in shallow depth pro files of boron. In Figure 10 this is the case for $D_{\text {BSG }}=10^{-12} \mathrm{~cm}^{2} / \mathrm{s}$ to $10^{-8} \mathrm{~cm}^{2} / \mathrm{s}$.

A high diffusivity of the dopants in the PECVD BSG layer $D_{\mathrm{BSG}}$ provides a high concentration of boron at the surface of the silicon substrate, see Figure 10. Conse quently, $D_{\mathrm{BSG}}$ can be determined from the surface concen tration of the dopants. For the dopant profiles $D_{\mathrm{BSG}}$ is estimated from $10^{-13}$ to $10^{-10} \mathrm{~cm}^{2} / \mathrm{s}$, independent of the phosphorus amount of the BSG layer [40]. This diffusivity allows for a sufficient transport of the dopants to the sur face of the substrate to work as an infinite doping source in the case of the boron profile, see Figure 5, and the phos phorus profile, see Figure 7.

\subsection{Back contact solar cell}

The simultaneous creation of differently doped regions in a silicon substrate [80] can be used for the production of a back contact solar cell [81] with a rear side $\mathrm{p} n$ junction $[82,83]$. Through the simultaneous in diffusion of phospho rus and boron [16] all necessary doped regions can be real ized during only one high temperature step.

To demonstrate this, $\mathrm{n}$ type silicon substrates with a full area BSG layer $\left(d_{\mathrm{BSG}}=27 \mathrm{~nm}\right)$ and a structured silicon nitride layer $\left(d_{\mathrm{SiN}}=70 \mathrm{~nm}\right)$ as a diffusion barrier for phos phorus on their rear side are prepared. During a sequential diffusion (a boron drive in step with $T>900^{\circ} \mathrm{C}$ followed by a $\mathrm{POCl}_{3}$ diffusion step with $T<850{ }^{\circ} \mathrm{C}$ ) in a $\mathrm{POCl}_{3}$ diffusion furnace a $\mathrm{p}^{+}$emitter doped positively with

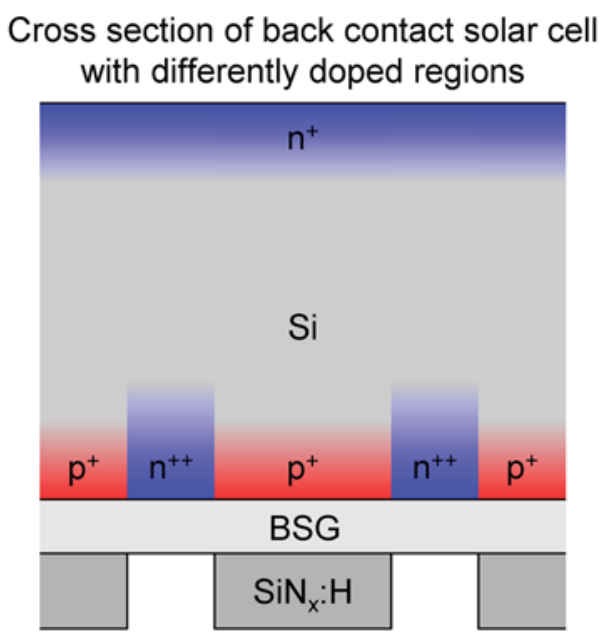

Figure 11. Sketched cross section of a silicon substrate (Si) with differently phosphorus $\left(\mathrm{n}^{+}, \mathrm{n}^{++}\right)$as well as boron doped $\left(\mathrm{p}^{+}\right)$regions for the fabrication of a back contact solar cell. The rear side of the substrate is covered by a full area borosil icate glass layer (BSG) and a structured silicon nitride layer $\left(\mathrm{SiN}_{\mathrm{x}}: \mathrm{H}\right)$ as diffusion barrier. Three differently doped regions form during one BSG diffusion step in a coated $\mathrm{POCl}_{3}$ diffusion furnace. boron forms in the areas with $\mathrm{SiN}_{\mathrm{x}}: \mathrm{H}$ layer, whereas in the unmasked areas a $\mathrm{n}^{++}$BSF $[3,84]$ heavily doped with phosphorus, and on the front side of the substrate $\mathrm{a}^{+}$ front surface field (FSF) [85] forms. The doping struc ture of the silicon substrate produced like this is shown in Figure 11.

The sheet resistivities and the doping profiles of the dif ferent regions correspond to those of identically processed full area silicon substrates. Also the results hold essentially for $\mathrm{p}$ and $\mathrm{n}$ type substrates as well as for invertedly masked structures. Average sheet resistivities of $39 \Omega / \square$ for the $\mathrm{p}^{+}$region, $19 \Omega / \square$ for the $\mathrm{n}^{++}$region and $48 \Omega / \square$ for the $\mathrm{n}^{+}$region were obtained.

The dopant profiles of the three regions can be further optimized by applying a co diffusion step (a boron drive in step with a $\mathrm{POCl}_{3}$ flow starting at a certain time of the step) in a coated $\mathrm{POCl}_{3}$ diffusion furnace. Using the developed model of the simultaneous diffusion of boron and phosphorus, an adjustment of the BSG layer thick ness and the process temperature and duration can be carried out to obtain desired profiles for the three regions.

\section{CONCLUSION}

This study reveals the interacting diffusion phenomena of boron and phosphorus in silicon. Co diffusion processes of boron and phosphorus through a BSG layer are investi gated experimentally. Key findings are: An overlying BSG layer does not prevent the formation of a phosphorus emit ter in silicon substrates during phosphorus diffusion, and it can even enhance the uptake of phosphorus into a silicon substrate compared to a bare substrate.

Based on these findings and known models of the diffu sivities of boron and phosphorus a model allowing for the prediction of co diffused dopant profiles is presented. Furthermore, a potentially industrially feasible process to fabricate three diverse phosphorus $\mathrm{n}^{++}, \mathrm{n}^{+}$, and boron $\mathrm{p}^{+}$doped regions during one single high temperature step is introduced for the production of highly efficient inter digitated back contact silicon solar cells.

\section{ACKNOWLEDGEMENTS}

Part of this work was financially supported by the German Federal Ministry for the Environment, Nature Conserva tion and Nuclear Safety (FKZ 0325581).

\section{REFERENCES}

1. NPD Solarbuzz. PV technology road map. (September 2014). http://www.solarserver.com/solar magazine/solar news/archive 2014/2014/kw42/npd solarbuzz efficiency enhancements to define solar pv technology roadmap for the next five years.html (Accessed on 19 January 2016). 
2. Fraunhofer Institute for Solar Energy Systems ISE. Annual report 2013/2014. Freiburg (2014). http://www.ise fraun hofer.de/de/veroeffentlichungen/veroeffentlichungen pdf dateien/infomaterial/jahresberichte/fraunhofer ise jahresbericht 2013 14.pdf

3. Mandelkorn J, Lamneck Jr., JH. Simplified fabrication of back surface electric field silicon solar cells and novel characteristics of such cells. Proceedings IEEE PVSC Silver Springs 1972; 66. DOI: 10.1016/0379 6787(90)90021 V

4. International technology roadmap for photovoltaic (Fifth edition), 2013 Results. 2014. http://www.itrpv. net/Reports/Downloads/

5. Gatz S. Analysis and Optimisation of Industrial Type Rear Passivated Silicon Solar Cells. Dissertation, Uni versity of Hannover 2013.

6. Smith D, Cousins P, Westerberg S, De Jesus Tabajonda $\mathrm{R}$, Aniero G, Shen Y C. Toward the practical limits of silicon solar cells. IEEE Journal of Photovoltaics 2014; 4: 1465. DOI:10.1109/JPHOTOV.2014.2350695

7. Benick J, Rentsch J, Schetter C, Voyer C, Biro D, Preu R. PECVD PSG as a dopant source for industrial solar cells. Proceedings EU PVSEC 2006; 1012.

8. Cabal R, Jourdan J, Grange B, Veschetti Y, Heslinga D. Investigation of the potential of boron doped oxide deposited by PECVD application to advanced solar cells fabrication processes. Proceedings EUPVSEC Hamburg 2009; 1605. DOI: 10.4229/ 24thEUPVSEC2009 2CV.2.52

9. Bazer Bachi B, Oliver C, Semmache B, Pellegrin Y, Gauthier M, Le Quang N, Lemiti M. Co diffusion from boron doped oxide and $\mathrm{POCl}_{3}$. Proceedings $E U$ PVSEC Hamburg 2011; 1155. DOI: 10.4229/ 26thEUPVSEC2011 2DO.2.4

10. Fallisch A, Wagenmann D, Keding R, Trogus D, Hof mann M, Rentsch J, Reinecke H, Biro D. Analysis of phosphorus doped silicon oxide layers deposited by means of PECVD as a dopant source in diffusion pro cesses. IEEE Journal of Photovoltaics 2012; 2: 450. DOI:10.1109/JPHOTOV.2012.2200455

11. Babics M, Cortés Juan F, Ponce Alcántara S, Cubero O, Sánchez G. Optimization and development of a new IBC process with only one diffusion step. Pro ceedings EUPVSEC Frankfurt 2012; 1700. DOI: 10.4229/27thEUPVSEC2012 2CV.5.21

12. Rothhardt P, Keding R, Wolf A, Biro D. Co diffusion from solid sources for bifacial $\mathrm{n}$ type solar cells. Physica status solidi Rapid Research Letters 2013; 7: 623. DOI:10.1002/pssr.201308055

13. Fritz S, Riegel S, Gloger S, Kohler D, König M, Hörtheis M, Hahn G. Influence of emitter properties on contact formation to $\mathrm{p}+$ silicon. Energy Procedia 2013; 38: 720. DOI:10.1016/j.egypro.2013.07.338
14. Frey A, Engelhardt J, Fritz S, Gloger S, Hahn G, Terheiden B. N type bifacial solar cells with boron emitters from doped PECVD layers. Proceedings EU PVSEC Amsterdam 2014; 656. DOI: 10.4229/EUPV SEC20142014 2DO.4.5

15. Engelhardt J, Frey A, Gloger S, Hahn G, Terheiden B. Passivating boron silicate glasses for co diffused high efficiency n type silicon solar cell application. Applied Physics Letters 2015; 107: 042102. DOI:10.1063/ 1.4927667

16. Keding R, Stüwe D, Kamp M, Reichel C, Wolf A, Woehl R, Borchert D, Reinecke H, Biro D. Co diffused back contact back junction silicon solar cells without gap regions. IEEE Journal of Photovoltaics 2013; 3: 1236. DOI:10.1109/JPHOTOV.2013.2274382

17. Wehmeier N, Schraps G, Wagner H, Lim B, Harder N P, Altermatt PP. Boron doped PECVD silicon oxides as diffusion sources for simplified high efficiency solar cell fabrication. Proceedings EU PVSEC Paris, 19802013. DOI: 10.4229/28thEUPVSEC2013 2DV.3.52

18. Engelhardt J, Frey A, Mahlstaedt L, Gloger S, Hahn G, Terheiden B. Boron emitters from doped PECVD layers for $\mathrm{n}$ type crystalline silicon solar cells with LCO. Energy Procedia 2014; 55: 235. DOI:10.1016/ j.egypro.2014.08.050

19. Frey A, Engelhardt J, Micard G, Hahn G, Terheiden B. Investigation of fill factor losses on $20.2 \%$ efficient n type mono like silicon solar cells with laser con tact opening. Physica Status Solidi (RRL) 2015. DOI:10.1002/pssr.201510334

20. Matano C. On the relation between the diffusion coefficients and concentrations of solid metals (the nickel copper system). Japanese Journal of Physics 1933; 8: 109.

21. Pichler P. Intrinsic Point Defects, Impurities, and Their Diffusion in Silicon. Springer: Wien, 2004. DOI: 10.1007/978 3709105979

22. Bentzen A. Phosphorus diffusion and gettering in silicon solar cells. Dissertation, University of Oslo 2006.

23. Micard G, Dastgheib Shirazi A, Raabe B, Hahn G. Diffusivity analysis of $\mathrm{POCl}_{3}$ emitter SIMS profiles for semi empirical parametrization in Sentaurus Pro cess. Proceedings EU PVSEC Hamburg, 2011; 1446. DOI: $10.4229 / 26$ thEUPVSEC2011 2BV.2.16

24. Synopsys Inc. Sentaurus. Mountain View 2014. http:// synopsys.com/Tools/TCAD/Pages/default.aspx

25. Altermatt PP. Models for numerical device simulations of crystalline silicon solar cells a review. Journal of Computational Electronics 2011; 10: 314. DOI:10.1007/ s108250110367 6

26. PDE Solutions Inc. FlexPDE 6.35. Spokane Valley 2014. http:Iwww.pdesolutions.com 
27. Zienkiewicz OC, Taylor RL. The Finite Element Method, Fifth edn. Butterworth Heinemann: Oxford, 2000.

28. Miyake M. Oxidation enhanced diffusion of ion implanted boron in heavily phosphorus doped silicon. Journal of Applied Physics 1985; 58: 711. DOI:10.1063/ 1.336311

29. Willoughby AFW, Evans AGR, Champ P, Yallup KJ, Godfrey DJ, Dowsett MG. Diffusion of boron in heavily doped $\mathrm{n}$ and $\mathrm{p}$ type silicon. Journal of Applied Physics 1986; 59: 2392. DOI:10.1063/ 1.336340

30. John JP, Law ME. Phosphorus diffusion in isoconcentration backgrounds under inert conditions in silicon. Applied Physics Letters 1993; 62: 1388. DOI:10.1063/1.108688

31. Wittel F, Dunham S. Diffusion of phosphorus in arse nic and boron doped silicon. Applied Physics Letters 1995; 66: 1415. DOI:10.1063/1.113219

32. Wagner H, Dastgheib Shirazi A, Chen R, Dunham ST, Kessler M, Altermatt PP. Improving the predictive power of modeling the emitter diffusion by fully including the phosphosilicate glass (PSG) layer. Proceedings IEEE PVSC Seattle. 2011; 2957. DOI:10.1109/PVSC.2011.6186566

33. Chen R, Wagner H, Dastgheib Shirazi A, Kessler M, Zhu Z, Shutthanandan V, Altermatt PP, Dunham ST. A model for phosphosilicate glass deposition via $\mathrm{POCl}_{3}$ for control of phosphorus dose in Si. Journal of Applied Physics 2012; 112: 124912. DOI:10.1063/ 1.4771672

34. Fair RB. Concentration profiles of diffused dopants in silicon. In Materials Processing Theory and Practices 2: Impurity Doping Processes in Silicon, Wang FFY (ed). North Holland Publishing Company: Amsterdam, 1981.

35. Fahey P, Griffin P, Plummer J. Point defects and dop ant diffusion in silicon. Reviews of Modern Physics 1989; 61: 289. DOI:10.1103/RevModPhys.61.289

36. Uematsu M. Simulation of boron, phosphorus, and ar senic diffusion in silicon based on an integrated diffu sion model, and the anomalous phosphorus diffusion mechanism. Journal of Applied Physics 1997; 82: 2228. DOI:10.1063/1.366030

37. Ural A, Griffin PB, Plummer JD. Fractional contribu tions of microscopic diffusion mechanisms for common dopants and self diffusion in silicon. Journal of Applied Physics 1999; 85: 6440. DOI:10.1063/1.370285

38. Fair RB, Tsai JCC. A quantitative model for the diffu sion of phosphorus in silicon and the emitter dip effect. Journal of the Electrochemical Society 1977; 124: 1107. DOI:10.1149/1.2133492

39. Gloger S. Functional layers from plasma enhanced chemical vapor deposition for crystalline silicon solar cells. Dissertation, University of Konstanz 2015. http://nbn resolving.de/urn:nbn:de:bsz:352 0299956

40. Nassau K, Levy RA, Chadwick DL. Modified phosphosilicate glasses for VLSI applications. Jour nal of the Electrochemical Society 1985; 132: 409. DOI:10.1149/1.2113853

41. Kern W, Schnable GL. Chemically vapor deposited borophosphosilicate glasses for silicon device applica tions. RCA Review 1982; 43: 423.

42. Gossmann H J, Haynes TE, Stolk PA, Jacobson DC, Gilmer GH, Poate JM, Luftman HS, Mogi TK, Thompson MO. The interstitial fraction of diffusivity of common dopants in Si. Applied Physics Letters 1997; 71: 3862. DOI:10.1063/1.120527

43. Zangenberg NR, Fage Pedersen J, Hansen JL, Larsen AN. Boron and phosphorus diffusion in strained and relaxed $\mathrm{Si}$ and SiGe. Journal of Applied Physics 2003; 94: 3883. DOI:10.1063/1.1602564

44. Holmes PJ. The use of etchants in assessment of semi conductor crystal properties. Proceedings of the IEE Part B: Electronic and Communication Engineering 1959; 106: 861. DOI:10.1049/pi b 2.1959.0160

45. Robbins H, Schwartz B. Chemical etching of silicon: II. The system $\mathrm{HF}, \mathrm{HNO}_{3}, \mathrm{H}_{2} \mathrm{O}$, and $\mathrm{HC}_{2} \mathrm{H}_{3} \mathrm{O}_{2}$. Journal of the Electrochemical Society 1960; 107: 108. DOI:10.1149/1.2427617

46. Schwartz B, Robbins H. Chemical etching of silicon: III. A temperature study in the acid system. Journal of the Electrochemical Society 1961; 108: 365. DOI:10.1149/1.2428090

47. Bogenschütz AF. Ätzpraxis für Halbleiter. Carl Hanser Verlag: München, 1967.

48. Kern W, Puotinen D. Cleaning solutions based on hydrogen peroxide for use in silicon semiconductor technology. RCA Review 1970; 31: 187.

49. Kern W. The evolution of silicon wafer cleaning tech nology. Journal of the Electrochemical Society 1990; 137: 1887. DOI:10.1149/1.2086825

50. Reif R, Kern W. Plasma enhanced chemical vapor de position. In: Thin Film Processes II. Vossen JL, Kern W (eds). Academic Press: San Diego 1991.

51. Woollam JA, Snyder PG, Rost MC. Variable angle spectroscopic ellipsometry: a non destructive charac terization technique for ultrathin and multi layer mate rials. Thin Solid Films 1988; 166: 317. DOI:10.1016/ 0040 6090(88)90393 8

52. Valdes LB. Resistivity measurements on germanium for transistors. Proceedings of the IRE 1954; 42: 420. DOI:10.1109/JRPROC.1954.274680

53. Ambridge T, Faktor MM. An automatic carrier con centration profile plotter using an electrochemical technique. Journal of Applied Electrochemistry 1975; 5: 319. DOI:10.1007/BF00608796 
54. Schroder DK. Semiconductor Material and Device Characterization, Third edn. Wiley: Hoboken, 2006.

55. Vick GL, Whittle KM. Solid solubility and diffusion coefficients of boron in silicon. Journal of the Electro chemical Society 1969; 116: 1142. DOI:10.1149/ 1.2412239

56. Armigliato A, Nobili D, Ostoja P, Servidori M, Solmi S. Solubility and precipitation of boron in silicon and supersaturation resulting by thermal predeposition. In Semiconductor Silicon, Huff HR, Sirtl E (eds). The Electrochemical Society: Princeton, 1977.

57. Ryssel H, Müller K, Haberger K, Henkelmann R, Jahnel F. High concentration effects of ion implanted boron in silicon. Applied Physics 1980; 22: 35. DOI: 10.1007/BF00897929

58. Garben B, Orr Arienzo WA, Lever RF. Investigation of boron diffusion from polycrystalline silicon. Jour nal of the Electrochemical Society 1986; 133: 2152. DOI:10.1149/1.2108359

59. Grove AS. Physics and Technology of Semiconductor Devices. Wiley: New York, 1967.

60. Micard G, Dastgheib Shirazi A, Steyer M, Wagner H, Altermatt P, Hahn G. Advances in the understanding of phosphorus silicate glass (PSG) formation for accu rate process simulation of phosphorus diffusion. Pro ceedings EU PVSEC Frankfurt 2012; 1355. DOI: 10.4229/27thEUPVSEC2012 2BV.5.8

61. Miyake M. Diffusion of boron into silicon from boro silicate glass using rapid thermal processing. Journal of the Electrochemical Society 1991; 138: 3031. DOI:10.1149/1.2085361

62. Sah CT, Sello H, Tremere DA. Diffusion of phospho rus in silicon oxide film. Journal of Physics and Chem istry of Solids 1959; 11: 288. DOI:10.1016/0022 3697 (59)90229 X

63. Horiuchi S, Yamaguchi J. Diffusion of boron in silicon through oxide layer. Japanese Journal of Applied Physics 1962; 1: 314. DOI:10.1143/JJAP.1.314

64. Doo VY. Silicon nitride, a new diffusion mask. IEEE Transactions on Electron Devices 1966; 13: 561. DOI:10.1109/T ED.1966.15735

65. Fränz I, Langheinrich W. The investigation of phos phorus diffusion in evacuated, sealed tubes using tracer methods. Solid State Electronics 1971; 14: 835. DOI:10.1016/S0038 1101(71)80009 6

66. Gloger S, Riegel S, Raabe B, Hahn G. Investigation of the back side passivation layer of screen printed bifacial silicon solar cells. Proceedings EU PVSEC Ham burg, 2009; 1544. DOI: 10.4229/24thEUPVSEC2009 2CV.2.40

67. Martin SW, Angell CA. On the glass transition and vis cosity of phosphorus pentoxide. The Journal of Physical Chemistry 1986; 90: 6736. DOI:10.1021/j100283a030
68. Sunami H, Itoh Y, Sato K. Stress and thermal expansion coefficient of chemical vapor deposited glass films. Journal of Applied Physics 1970; 41: 5115. DOI:10.1063/1.1658622

69. Learn AJ, Baerg B. Growth of borosilicate and borophosphosilicate films at low pressure and temper ature. Thin Solid Films 1985; 130: 103. DOI:10.1016/ 0040 6090(85)90300 1

70. Kern W, Hartman J. Simultaneous deposition and fusion flow planarization of borophosphosilicate glass in a new chemical vapor deposition reactor. Thin Solid Films 1991; 206: 64. DOI:10.1016/0040 6090(91) 90394 D

71. Hu SM, Fahey P, Dutton RW. On models of phospho rus diffusion in silicon. Journal of Applied Physics 1983; 54: 6912. DOI:10.1063/1.331998

72. Bentzen A, Holt A, Christensen JS, Svensson BG. High concentration in diffusion of phosphorus in $\mathrm{Si}$ from a spray on source. Journal of Applied Physics 2006; 99: 064502. DOI:10.1063/1.2179197

73. Bentzen A, Christensen JS, Svensson BG, Holt A. Un derstanding phosphorus emitter diffusion in silicon so lar cell processing. Proceedings EU PVSEC Dresden, 13882006.

74. Fair RB. Boron diffusion in silicon concentration and orientation dependence, background effects, and pro file estimation. Journal of The Electrochemical Society 1975; 122: 800. DOI:10.1149/1.2134326

75. Mathiot D, Pfister JC. Dopant diffusion in silicon: A consistent view involving nonequilibrium defects. Journal of Applied Physics 1984; 55: 3518. DOI:10.1063/1.332941

76. Morehead FF, Lever RF. Enhanced "tail" diffusion of phosphorus and boron in silicon: self interstitial phe nomena. Applied Physics Letters 1986; 48: 151. DOI:10.1063/1.96980

77. Cowern NEB, Godfrey DJ. A model for coupled dopant diffusion in silicon. The international journal for com putation and mathematics in electrical and electronic engineering 1987; 6: 59. DOI:10.1108/eb010302

78. Ghoshtagore RN. Phosphorus diffusion processes in $\mathrm{SiO}_{2}$ films. Thin Solid Films 1975; 25: 501. DOI:10.1016/0040 6090(75)90068 1

79. Schön J, Abdollahinia A, Müller R, Benick J, Hermle M, Warta W, Schubert MC. Predictive sim ulation of doping processes for silicon solar cells. Energy Procedia 2013; 38: 312. DOI:10.1016/j. egypro.2013.07.283

80. Jain GC, Singh SN, Kotnala RK, Arora NK. Fabrica tion of $\mathrm{p}+\mathrm{n} \mathrm{n}+$ silicon solar cells by simultaneous diffusion of boron and phosphorus into silicon through silicon dioxide. Journal of Applied Physics 1981; 52: 4821. DOI:10.1063/1.329324 
81. Van Kerschaver E, Beaucarne G. Back contact solar cells: a review. Progress in Photovoltaics: Research and Applications 2006; 14: 107. DOI:10.1002/pip.657

82. Schwartz RJ, Lammert MD. Silicon solar cells for high concentration applications. Proceedings International Electron Devices Meeting 1975; 21: 350. DOI:10.1109/ IEDM.1975.188896

83. Lammert M, Schwartz RJ. The interdigitated back con tact solar cell: a silicon solar cell for use in concentrated sunlight. IEEE Transactions on Electron Devices 1977; 24: 337. DOI:10.1109/T ED.1977.18738

84. Godlewski MP, Baraona CR. Low high junction the ory applied to solar cells. Proceedings IEEE PVSC Palo Alto, 1973; 40. DOI: 10.1016/0379 6787(90) $90022 \mathrm{~W}$

85. Von Roos O, Anspaugh B. The front surface field solar cell, a new concept. Proceedings IEEE PVSC Washington D.C., 1978; 1119. 